\title{
Agreement between the total energy expenditure calculated with accelerometry data and the BMR yielded by predictive equations $v$. the total energy expenditure obtained with doubly labelled water in low-income women with excess weight
}

\author{
Mateus L. Macena ${ }^{1}$, Isabele R. O. M. Pureza ${ }^{1}$, Ingrid S. V. Melo ${ }^{2}$, Ana G. Clemente ${ }^{1}$, Haroldo S. Ferreira ${ }^{1}$, \\ Telma M. M. T. Florêncio ${ }^{1}$, Karina Pfrimer $^{3}$, Eduardo Ferrioli ${ }^{3}$, Ana L. Sawaya ${ }^{4}$ and Nassib B. Bueno ${ }^{1 *}$ \\ ${ }^{1}$ Faculdade de Nutrição, Universidade Federal de Alagoas, Maceió, AL 57072-900, Brazil \\ ${ }^{2}$ Departamento de Agroindústria, Instituto Federal de Alagoas, Satuba, AL 57120-000, Brazil \\ ${ }^{3}$ Faculdade de Medicina de Ribeirão Preto, Universidade de São Paulo, Ribeirão Preto, SP 14049-900, Brazil \\ ${ }^{4}$ Departamento de Fisiologia, Universidade Federal de São Paulo, São Paulo, SP 04021-001, Brazil \\ (Submitted 22 February 2019 - Final revision received 3 September 2019 - Accepted 9 September 2019)
}

\section{Abstract}

Low-income women are the group with the highest levels of obesity worldwide. In low-income settings, the use of predictive equations, which yield a measure of the individuals' BMR, is a feasible approach to estimate the individuals' total energy expenditure (TEE), using the factorial method (calculated-TEE $=$ BMR $\times$ physical activity level), an important step of the obesity nutritional care. The present study aimed to identify the predictive equation that, in conjunction with metabolic equivalents of tasks (MET) data from accelerometers, yields the calculated-TEE with better agreement compared with the TEE measured by doubly labelled water (TEE-DLW). Forty-five women aged 19-45 years, with excess weight and mothers of undernourished children, were included. They received DLW to determine TEE (14 d); at the same time, they used triaxial accelerometers $(7 \mathrm{~d})$ to estimate their MET. The Bland-Altman method, paired-sample $t$ tests, concordance correlation coefficient and rootmean-square error were used to assess the agreement. Maximum allowed differences were defined as $24 \%$, based on the within-variance coefficient of the energy intake of the sample. Eleven equations were studied. The calculated-TEE obtained by five equations showed non-significant bias: Dietary Reference Intake (Institute of Medicine (2005) Dietary Reference Intakes for Energy, Carbohydrate, Fiber, Fat, Fatty Acids, Cholesterol, Protein, and Amino Acids), FAO/WHO/UNU ((2001) Food and Nutrition Technical Report Series), Harris \& Benedict ((1919) Proc Natl Acad Sci USA 4, 370-373), Henry \& Rees ((1991) Eur J Clin Nutr 45, 177-185) and Schofield ((1985) Hum Nutr Clin Nutr 39, $5-41)$. The mean percentage differences were $-1 \cdot 5,-0 \cdot 8,2 \cdot 2,-2 \cdot 2$ and $2 \cdot 0 \%$, respectively. Considering all parameters, FAO/WHO/UNU ((2001) Food and Nutrition Technical Report Series) equation performed slightly better than the others; nevertheless, no equation in conjunction with the estimated-MET showed a calculated-TEE with its CI for the Bland-Altman limits of agreement inside the pre-defined acceptable range.

Key words: Doubly labelled water: Energy expenditure: Predictive equations: Dietary plans: Physical activity level

Estimates indicate that by the year $2013,62 \%$ of the obese population of the world lived in low- and middle-income countries ${ }^{(1)}$. It is also known that young adult women are the group with the highest increase in excess weight prevalence in these countries ${ }^{(2)}$. In Brazil, national surveys indicate that there is an interaction between formal education levels, a proxy of income and excess weight prevalence in women. Those women with fewer years of formal education present the highest and still increasing prevalence of excess weight, whereas those with more years of formal education show the lowest and stagnated prevalence ${ }^{(3)}$.
It is considered that weight gain arises from an energy imbalance, defined as when the energy intake of an individual exceeds his/her total energy expenditure (TEE). TEE is composed of the sum of the BMR, the physical activity (PA) energy expenditure and the thermic effect of food. Hence, it is a pivotal step of the nutritional care to adequately estimate the TEE of any individual seeking to lose weight, so that an energy deficit may be established ${ }^{(4,5)}$.

There is a myriad of methods available to assess TEE, being the doubly labelled water (DLW) usually considered the 'gold

Abbreviations: CCC, concordance correlation coefficient; DLW, doubly labelled water; DRI, Dietary Reference Intakes; MET, metabolic equivalents of tasks; PA, physical activity; PAL, PA level; TEE, total energy expenditure.

* Corresponding author: Nassib B. Bueno, email nassib.bueno@fanut.ufal.br 
standard' one ${ }^{(6)}$. Nonetheless, this method has a high operational cost, turning its use in large studies and clinical practice prohibitive $^{(7)}$. Hence, clinicians and researchers frequently use other methods that yield an estimate of the TEE in order to estimate the daily energy requirement of individuals. The use of predictive equations is rapid and smooth, with no associated costs, being the most feasible method to be used with outpatients, especially in low-income settings. However, its results are often discrepant, given that different equations were built using diverse populations and methods. In addition, few studies have validated the use of these equations in low-income populations.

Furthermore, these equations do not estimate the TEE itself, but rather, it usually estimates the BMR or the $\mathrm{RMR}^{(8,9)}$. Briefly, the BMR is the rate of energy expenditure that occurs while the individual is at rest, in the post-absorptive state (12-14 h after food intake), thus, without the influence of recent food intake and $\mathrm{PA}^{(5)}$. In turn, RMR tends to be somewhat higher (10-20\%) than the BMR since it is affected by recent food intake and recent $\mathrm{PA}^{(5)}$. Predictive equations usually extrapolate the resulting BMR or RMR to a 24-h period, expressed in $\mathrm{kJ} / 24-\mathrm{h}$, to be more meaningful, referred to as the basal energy expenditure or the resting energy expenditure, respectively ${ }^{(5)}$. Noteworthy, these terms are often used interchangeably in the literature; hence, studies may state that the same predictive equation yields an estimate of the $\mathrm{BMR}^{(10)}$ or the $\mathrm{RMR}^{(11)}$ or of the resting energy expenditure ${ }^{(12)}$, making it challenging to maintain a constant nomenclature use.

Nevertheless, in clinical practice, it is more useful to estimate the TEE and not the BMR, since the energy deficit, as already pointed out, must be calculated considering the $\mathrm{TEE}^{(13)}$. Hence, clinicians and researchers need to multiply the result of such an equation by a factor that represents the PA energy expenditure of the individuals. This factor is also known as the PA level (PAL), which is the ratio between TEE and BMR, expressed as multiples of BMR. Nevertheless, it is also a challenge to estimate PA energy expenditure, and consequently $\mathrm{PAL}$, in clinical practice, since it is difficult to be objectively measured. Given that the use of accurate methods, such as triaxial accelerometers, is also expensive, the use of questionnaires, which are usually imprecise, is common ${ }^{(14)}$

Hence, the objective of the present study was to determine, in low-income women with excess weight, which calculated-TEE, obtained through the multiplication of the BMR resulting from different predictive equations by the metabolic equivalent of task (MET) obtained with triaxial accelerometers, shows higher agreement compared with the TEE obtained with the use of DLW (TEE-DLW).

\section{Methods \\ Ethical aspects}

The human experimental procedures conducted were all approved by the Ethical in Research Committee of the Centro de Estudos Superiores de Maceió, under protocol number 1588/12. All women provided written consent to participate in the study.

\section{Population and sample}

Low-income women with excess weight (BMI > 25 and $<40 \mathrm{~kg} / \mathrm{m}^{2}$ ), aged 19-45 years, were included, using a nonprobabilistic, convenience sampling approach. These women are mothers of undernourished children treated at the Centre for Nutrition Education and Recovery, a non-governmental institution, which aims to nutritionally recover undernourished children, located in a shantytown on the outskirts of Maceió-AL, a city with approximately 1 million inhabitants and a homicide rate of sixty-four per 100000 per year in 2017. In the specific region of the shantytown, Human Development index is lower than $0 \cdot 600$, with a severe lack of infrastructure. Individuals living there usually come from the countryside, with an almost complete absence of a social network, since they do not bring any family or friend with them.

All mothers were invited to a screening at the centre. Pregnant and lactating women, those with physical impairment that interfered with anthropometric evaluation, those who self-reported to be dieting or presented with weight change in the previous month or during the $14 \mathrm{~d}$ of DLW assessment, and those who reported doing upper-body weight-resisted exercise, which cannot be detected by the triaxial accelerometers, were not included. All women underwent blood collection to determine concentrations of thyroid hormones, fasting blood glucose and insulin, and those with altered parameters were not included. Those who reported using antidiabetic or diuretic drugs or were doing thyroid hormones replacement were also not included.

\section{Socio-economic and demographic data}

A structured questionnaire was used to assess primary socioeconomic and demographic data, such as age, years of formal schooling, number of children, the household crowding index (the number of individuals living in the household divided by the number of rooms in the household), labour situation and if the household receives financial aid from the government ${ }^{(15)}$.

\section{Anthropometric measurements}

Body weight was measured using a digital scale (Filizola), and height was measured using a portable stadiometer ${ }^{(16)}$. BMI was calculated and classified according to the WHO cut-off points ${ }^{(16)}$.

\section{Dietary intake data}

Energy intake was estimated through the application of three 24-h dietary recalls in each participant, one of which at weekend day, with the aid of a photo book to assist in the quantification of food portions ${ }^{(17)}$. In order to take into account the within-subject variance in the multiple 24-h dietary recalls, the de-attenuation method was used ${ }^{(5)}$. The same nutritionist undertook all the 24-h dietary recalls via in-person interviews and performed the coding and analysis of dietary assessments. More details can be found in another publication of the present study ${ }^{(18)}$. 


\section{Doubly labelled water analysis}

The TEE of the participants was estimated using the multiplepoint DLW $\left({ }^{2} \mathrm{H}_{2}{ }^{18} \mathrm{O}\right)$ technique, according to the recommendations of the International Dietary Energy Consultancy Group ${ }^{(19)}$. In order to receive the DLW dosage, the volunteers could not be febrile, present oedema, should neither have practised intense exercises the day before nor have received intravenous fluids the week before the study. Also, they could not travel outside the State of Alagoas within $14 \mathrm{~d}$ after the administration, as this would cause a change in the source of drinking water. Initially, a 10-h fasting urine sample of all participants was collected to serve as isotope-free basal urine. Then, all women received a single dose of DLW. The dose of DLW was formulated considering the estimated total body water of the included women and was composed of $0 \cdot 12 \mathrm{~g}$ of $99 \cdot 8 \%{ }^{2} \mathrm{H}$-labelled water and $2 \mathrm{~g}$ of $10 \%$ ${ }^{18} \mathrm{O}$-labelled water $\mathrm{kg}$ of estimated body water. Body water was assumed to be $50 \%$ of the women's body weight ${ }^{(20)}$. Next, urine samples of each volunteer were collected on the 1st, 2nd, 3rd, 7 th, 12th, 13th and 14th day after dose administration.

Isotopic analysis of the samples by isotope ratio MS for ${ }^{18} \mathrm{O}$ (ANCA 20-20; Europe Scientific) and for ${ }^{2} \mathrm{H}$ (ANCA 20-22; Sercon) was performed at the Mass Spectrometry Laboratory of the School of Medicine of Ribeirão Preto, which is accredited by the International Atomic Energy Agency. The ${ }^{2} \mathrm{H}$ and ${ }^{18} \mathrm{O}$ elimination rates were calculated according to Speakman ${ }^{(21)}$. Tap water was collected and analysed, and all calculations were adjusted for the content of isotopes in the drinking water. The rate of carbon dioxide production was calculated according to Coward et $a l .{ }^{(19)}$. The isotope dilution spaces and TEE were calculated by the comparison of the enrichment of the baseline sample with that of the $1 \mathrm{st}, 2 \mathrm{nd}, 3 \mathrm{rd}, 7 \mathrm{th}, 12 \mathrm{th}, 13 \mathrm{th}$ and 14 th day samples when a plateau of enrichment must have been reached. The enrichment of samples collected $14 \mathrm{~d}$ after dosing was used to draw the ${ }^{2} \mathrm{H}$ and ${ }^{18} \mathrm{O}$ elimination rate. A respiratory quotient of 0.85 was assumed to calculate TEE. The following criteria were established for the measurements: the ratio between the ${ }^{2} \mathrm{H}$ dilution space and the ${ }^{18} \mathrm{O}$ dilution space should be from 1.01 to 1.07 and the differences in the sample triplicates should be 5 deltas for ${ }^{2} \mathrm{H}$ and 0.5 deltas for ${ }^{18} \mathrm{O}^{(15,17)}$.

\section{Physical activity level}

In order to estimate the PAL of the participants, triaxial accelerometer motion sensors $\left(\right.$ ActivPAL $^{\circledR}$ ) were used. The participants used the equipment for seven consecutive days, in the anterior portion of their thigh, with the aid of an impermeable medical dressing (TegaDerm $\left.{ }^{\circledR}, 3 \mathrm{M}\right)$, during the DLW period, and were advised not to withdraw it until the end of the specified period. ActivPAL $^{\circledR}$ has been thoroughly validated in adults. It is a reliable measure during everyday physical activities of posture and motion $^{(22)}$, and of walking, with an absolute percentage error of approximately $1 \%$ for step number and cadence, regardless of walking speed ${ }^{(23)}$. It also accurately classifies activity intensity categories in healthy adults ${ }^{(24)}$, and it has been used as the criterion validity measure in studies of occupational sitting and standing ${ }^{(25)}$, sedentary behaviour ${ }^{(26)}$ and light-intensity $\mathrm{PA}^{(27)}$. Considering that mostly sedentary women composed our sample, we believe that ActivPAL ${ }^{\circledR}$ would be a reliable way of measuring their PAL.
ActivPAL ${ }^{\circledR}$ computes the time that the individuals spend lying/ sitting, standing, walking and running at every tenth of a second and then provides a MET estimate for the whole period of use based on default values for sitting/lying (1.25 MET), standing (1.40 MET) and stepping at a cadence of 120 steps per min (four MET). These MET values are taken from the WHO report ${ }^{(28)}$ and James \& Schofield ${ }^{(29)}$. The software analysis of the accelerometers' data provides the MET value for the entire period that the individuals wore them by multiplying the MET value for each activity by the duration of the activity. For cadences that differ from 120 steps per min, the following equation is used to compute the MET estimate: MET.h $=(1.4 \times d)+(4-1.4) \times(c / 120) \times d$, where $c$ is the cadence (steps per min) and $d$ is the activity duration (in h). The ActivPAL ${ }^{\circledR}$ internal equation performed reasonably well in estimating energy expenditure during treadmill walking in females aged $15-25$ years, especially in lower intensities' activities, which is the case of the sample from the present study ${ }^{(30)}$.

The MET value yielded by the accelerometer analysis is closely related to the physical activity ratio concept, which is used to estimate the PAL of an individual when using questionnaires of $\mathrm{PA}^{(31)}$. When one estimate PAL through questionnaires, it is necessary to record the time allocated (in $\mathrm{h}$ ) to different activities performed by the individual in a day (from time spent working in a sedentary job to physical exercise such as jogging or swimming) and multiply it by the reference values for MET for each of these activities. The result of this multiplication is then divided by the total hours (usually $24 \mathrm{~h}$ ) to yield the mean PAL of the individual, as a multiple of the $24-\mathrm{h} \mathrm{BMR}^{(31)}$. Proceeding in a similar way, in the present study, the total MET value obtained in the 7-d period of the accelerometer analysis was divided by the total amount of hours that the individuals used the accelerometer $(168 \mathrm{~h})$, yielding a proxy of the individual's PAL (estimated PAL), as a multiple of the 24-h BMR.

MET has a widely accepted definition of the amount of $\mathrm{O}_{2}$ consumed while sitting at rest and is equal to $3.5 \mathrm{ml}$ $\mathrm{O}_{2}$ per $\mathrm{kg}$ body weight $\times$ min, or as $4.184 \mathrm{~kJ} / \mathrm{kg}$ per $\mathrm{h}$, and is roughly equal to the cost of sitting quietly ${ }^{(32)}$. It is a simple concept that may express the energy cost of PA as a multiple of the RMR, regardless of individual characteristics and type of $\operatorname{activity}^{(33)}$. Nevertheless, there are several critiques regarding the adoption of this value for every individual, since it was obtained in a sitting 40 -year-old male adult ${ }^{(34)}$. More recently, the use of corrected MET values has been suggested, which would better represent the BMR of individuals, usually obtained as a multiple of supine RMR rather than seated RMR. Corrected MET values are systematically lower than the standard MET values ${ }^{(35)}$. In a similar sample of obese women from the same population of the present study, we found a mean amount of $\mathrm{O}_{2}$ consumption of $2.82 \mathrm{ml} / \mathrm{kg}$ body weight $\times$ min, which is roughly equal to $3.52 \mathrm{~kJ} / \mathrm{kg}$ per $\mathrm{h}$, considering $1 \mathrm{ml}$ of $\mathrm{O}_{2}$ consumed yields $20.92 \mathrm{~kJ}$, similar to the values reported by Byrne et al. ${ }^{(34)}$. These values were used in the present study in order to assess the accuracy and precision of the estimates of energy expenditure based on the MET values obtained from the accelerometry analysis; in other words, the estimated PAL obtained for each woman was multiplied by her body weight (in $\mathrm{kg}$ ), by $3.52(\mathrm{~kJ})$ and by $24(\mathrm{~h})$. 
Table 1. Predictive equations used to estimate energy expenditure in female populations found in the literature review $(n 11)$

\begin{tabular}{|c|c|c|}
\hline Equation & Year & Formulae* \\
\hline Anjos et al. ${ }^{(37)}$ & 2014 & $(8.95 \times$ weight $)+(8.87 \times$ height $)-(0.70 \times$ age $)-814.3$ \\
\hline $\mathrm{DRI}^{(5)}$ & 2005 & $448-(7.95 \times$ age $) \times$ physical activity $+(11.4 \times$ weight $+619 \times$ height $)$ \\
\hline $\mathrm{FAO} / \mathrm{WHO} / \mathrm{UNU}^{(31)}$ & 2001 & $\begin{array}{l}\text { a. } 18-30 \text { years: }(14.818 \times \text { weight })+486.6 \\
\text { b. } 31-60 \text { years: }(8.126 \times \text { weight })+845.6\end{array}$ \\
\hline Harris \& Benedict ${ }^{(36)}$ & 1919 & $655.0955+9.5634 \times($ weight +1.8496$) \times($ height -4.6756$) \times$ age \\
\hline Henry \& Rees ${ }^{(38)}$ & 1991 & $\begin{array}{l}\text { a. } 18-30 \text { years: }(0.048 \times \text { weight })+(2.562 \times 239) \\
\text { b. } 31-60 \text { years: }(0.048 \times \text { weight })+(2.448 \times 239)\end{array}$ \\
\hline Mifflin et al. ${ }^{(39)}$ & 1990 & $(9.99 \times$ weight $)+(6.25 \times$ height $)-(4.92 \times$ age $)-161$ \\
\hline Owen et al. ${ }^{(40)}$ & 1986 & $795+(7.18 \times$ weight $)$ \\
\hline Oxford $^{(8)}$ & 2005 & $\begin{array}{l}\text { a. } 18-30 \text { years: }(10.4 \times \text { weight })+(615 \times \text { height })-282 \\
\text { b. } 31-60 \text { years: }(8.18 \times \text { weight })+(502 \times \text { height })-11.6\end{array}$ \\
\hline Rodrigues et al. ${ }^{(41)}$ & 2010 & $\begin{array}{l}\text { a. } \mathrm{BMl}<35 \mathrm{~kg} / \mathrm{m}^{2}: 407.57+(9.58 \times \text { weight })+(2.05 \times \text { height })-(1.74 \times \text { age }) \\
\text { b. } \mathrm{BMI}>35 \mathrm{~kg} / \mathrm{m}^{2}: 172.19+(10.93 \times \text { weight })+(3.10 \times \text { height })-(2.55 \times \text { age })\end{array}$ \\
\hline Schofield ${ }^{(42)}$ & 1985 & $\begin{array}{l}\text { a. } 18-30 \text { years: }(0.062 \times \text { weight }+2.036) \times 239 \\
\text { b. } 31-60 \text { years: }(0.034 \times \text { weight }+3.538) \times 239\end{array}$ \\
\hline Siervo et al. ${ }^{(43)}$ & 2003 & $(11.5 \times$ weight $)+542.2$ \\
\hline
\end{tabular}

DRI, Dietary Reference Intakes.

* The unit of measurement for weight is $\mathrm{kg}$, for height is $\mathrm{cm}$, for age is years. For DRI and Oxford, the height was in metres.

\section{Calculation of estimated total energy expenditure}

In their seminal paper, Harris \& Benedict ${ }^{(36)}$ stated that BMR should be measured with the individual 'in a state of complete muscular repose 12-14 hours after the last meal'. Hence, in the present study, when the seminal paper of an equation reported that it was derived from indirect calorimetry measures conducted in individuals with at least 12-h fasting, the equation was considered to yield an estimation of the BMR. The only exception was the equation provided by the Dietary Reference Intake (DRI) ${ }^{(5)}$.

The following eleven predictive equations of the BMR of the participants were used in the present study, after a review of the recent literature of studies using equations to assess energy expenditure in female Brazilian populations: Anjos et $a l .{ }^{(37)}$, $\mathrm{DRI}^{(5)}$, FAO/WHO/UNU ${ }^{(31)}$, Harris \& Benedict ${ }^{(36)}$, Henry \& Rees $^{(38)}$, Mifflin et $a l .{ }^{(39)}$, Owen ${ }^{(40)}$, Oxford ${ }^{(8)}$, Rodrigues et $a l^{(41)}$, Schofield ${ }^{(42)}$ and Siervo et al. ${ }^{(43)}$. The formulae for these equations are found in Table 1. As the present investigation is intended to aid low-income settings, equations that use parameters that are not easily collected, such as lean mass and fat mass, were not included. The equation by Rodrigues et $a l .{ }^{(41)}$ does not clearly state if individuals were in 12-h fasting in the indirect calorimetry measurements. However, as it was conducted with a female Brazilian population, we included it in the present analysis.

The calculated-TEE of each participant was calculated using the factorial approach (i.e. TEE $=\mathrm{BMR} \times \mathrm{PAL})^{(13)}$. First, each predictive equation was calculated for each participant, yielding an estimated measure of the individuals' BMR. The equations that yielded results in kcal were transformed into $\mathrm{kJ}$, by multiplying it by $4 \cdot 184$. Then, this estimated BMR was multiplied by the estimated PAL yielded by the accelerometry analysis, for each participant, to yield the calculated-TEE. According to the FAO/WHO/UNU joint report ${ }^{(31)}$, thermic effect of food is already accounted for in the PAL when TEE is estimated using the factorial approach. The factorial method was not applied to the DRI equation. This equation contains a PA coefficient, which is based on the PAL, and predicts the estimated energy requirements of the individuals, which is already a proxy of the TEE. According to the equation instructions, the PA coefficient was equal to 1.00 if PAL was estimated to be $\geq 1 \cdot 0<1 \cdot 4$, equal to $1 \cdot 12$ if $\mathrm{PAL}$ was estimated $\geq 1 \cdot 4<1 \cdot 6$, equal to $1 \cdot 27$ if $\mathrm{PAL}$ was estimated to be $\geq 1.6<1.9$ and equal to 1.45 if PAL was estimated to be $\geq 1.9<2.5^{(5)}$.

\section{Statistical analyses}

Three different methods assessed the agreement between the calculated-TEE obtained with the predictive equations and accelerometry analysis and the TEE-DLW. Firstly, the method of Bland and Altman, using the percentage differences, was used, since it diminishes the proportionality bias in the analysis ${ }^{(44)}$. Limits of agreement and its $95 \%$ CI were calculated. In order to assess which calculated-TEE yielded by the equations did not present significant bias compared with the TEE-DLW, a paired-sample ' $t$ ' test between the calculated-TEE and the TEEDLW was conducted. Those equations that did not show significant differences between calculated-TEE and TEE-DLW were considered to present a non-significant bias. To determine the maximum allowed difference between methods in the Bland and Altman analysis, the within-subject variance coefficient of the energy dietary intake of the sample obtained with the use of three 24-h food records was used as a proxy, considering that, if the energy intake of an individual with stable body weight varies from day to day, the estimation of the TEE may also vary. This coefficient was $23.9 \%{ }^{(18)}$, so a maximum allowed difference of $24 \%$ was defined as acceptable.

Secondly, the root-mean-square error between each calculated-TEE and the TEE-DLW was calculated, in which the lowest values show better agreement between methods. Thirdly, the concordance correlation coefficient (CCC), which considers both the precision (the Pearson correlation coefficient) and the accuracy (using a bias correction factor that measures how far the best-fit line deviates from the $45^{\circ}$ line) for each pair of measurements, was also analysed ${ }^{(45)}$. The CCC equation is as follows: 
Table 2. Characteristics of the included women ( $n$ 45) (Mean values and standard deviations; frequencies and percentages)

\begin{tabular}{|c|c|c|}
\hline Variables & Mean & SD \\
\hline Age (years) & $31 \cdot 0$ & $5 \cdot 0$ \\
\hline Height (cm) & $155 \cdot 3$ & 7.3 \\
\hline Weight (kg) & $71 \cdot 3$ & 9.6 \\
\hline BMI $\left(\mathrm{kg} / \mathrm{m}^{2}\right)$ & $29 \cdot 6$ & $3 \cdot 2$ \\
\hline Formal schooling (years) & 6.9 & 3.6 \\
\hline Number of children & $2 \cdot 8$ & 1.5 \\
\hline Household crowding index & $1 \cdot 2$ & 0.8 \\
\hline Estimated PAL (24 h-multiple of BMR) & 1.47 & 0.06 \\
\hline Steps/d & $11443 \cdot 1$ & $4204 \cdot 7$ \\
\hline Lying/sitting (h/d) & $15 \cdot 0$ & 1.9 \\
\hline Standing $(\mathrm{h} / \mathrm{d})$ & $6 \cdot 5$ & 1.6 \\
\hline \multirow[t]{2}{*}{ Walking/running $(\mathrm{h} / \mathrm{d})$} & $2 \cdot 5$ & 0.8 \\
\hline & Frequency & $\%$ \\
\hline \multicolumn{3}{|l|}{ Labour situation } \\
\hline Housewife & 27 & $60 \cdot 0$ \\
\hline Informal working & 18 & $40 \cdot 0$ \\
\hline Household with uncovered floor & 22 & 48.9 \\
\hline $\begin{array}{l}\text { Household receiving financial aid } \\
\text { from the government }\end{array}$ & 37 & $82 \cdot 2$ \\
\hline \multicolumn{3}{|l|}{ BMI classification } \\
\hline Overweight $\left(25 \cdot 0-29.9 \mathrm{~kg} / \mathrm{m}^{2}\right)$ & 29 & 64.5 \\
\hline Obesity class I $\left(30.0-34.9 \mathrm{~kg} / \mathrm{m}^{2}\right)$ & 13 & $28 \cdot 8$ \\
\hline Obesity class II $\left(35.0-39.9 \mathrm{~kg} / \mathrm{m}^{2}\right)$ & 3 & 6.7 \\
\hline
\end{tabular}

PAL, physical activity level.

$$
\mathrm{CCC}=\frac{2 S_{X Y}}{S x+S y+(\bar{x}-\bar{y})^{2}}
$$

where $S_{X Y}=\operatorname{covariance}(X, Y), \quad S_{x}=\operatorname{var}(X), S_{y}=\operatorname{var}(Y)$. The Spearman rank correlation was used to explore the relationship between the PAL estimated with the accelerometers and the bias in the calculated-TEE using the predictive equations.

Sample size was determined according to the method of $\mathrm{Lu}$ et $a l .{ }^{(46)}$. Based on the study by Raveli et al. ${ }^{(47)}$, where the two best equations showed a mean difference of $2.5 \%$ compared with the TEE-DLW, and considering the mean TEE-DLW of our sample $(8983 \mathrm{~kJ})$, the expected mean of the differences for the present study would be $222 \mathrm{~kJ}$. In order to obtain a sample that yielded an $\alpha$ value of $5 \%$ and a $\beta$ value of $20 \%$, considering an expected standard deviation of three times the mean difference $(666 \mathrm{~kJ})$ and a maximum allowed difference of $24 \%$ $(2154 \mathrm{~kJ})$, the minimum required number of pairs for the Bland and Altman analysis would be thirty-one.

All analyses were conducted using the statistical package MedCalc Statistical Software version 18.11.3 (MedCalc Software bvba) and an $\alpha$ value of $5 \%$ was adopted.

\section{Results}

From the sixty-seven women who were mothers or relatives to the undernourished children treated at the centre and received a DLW dose in the study, nineteen were excluded from the present analysis due to being in the normal BMI range. From forty-eight remaining women, three were excluded due to presenting less than $7 \mathrm{~d}$ of accelerometer data, resulting in forty-five women included in the present investigation. Descriptive characteristics of the women are shown in Table 2. Regarding their estimated PAL, the lowest value was 1.35 and the highest value was 1.65. PAL categories were distributed as follows: Three women $(6.6 \%)<1.4$; forty women $(88.9 \%) \geq 1.4$ and $<1.6$ and two women $(4.4 \%) \geq 1 \cdot 6$. The agreement between the calculatedTEE yielded by the equations' results multiplied by the estimated-PAL yielded by the accelerometry analysis and the TEE-DLW is found in Table 3, which also shows the agreement between the estimates of energy expenditure based on the estimated PAL yielded by the accelerometer analysis and the TEE-DLW.

Accelerometry derived estimates of energy expenditure showed good agreement with the TEE-DLW, with a bias of $-1 \cdot 2 \%$ and a CCC of $0 \cdot 60$. Considering all eleven equations, only five provided a calculated-TEE that did not present a significant bias compared with the TEE-DLW: DRI ${ }^{(5)}$, FAO/WHO/ $\mathrm{UNU}^{(31)}$, Harris \& Benedict ${ }^{(36)}$, Henry \& Rees ${ }^{(38)}$ and Schofield ${ }^{(42)}$. The mean percentage difference and limits of agreement between the calculated-TEE of each of these equations and the TEE-DLW were $1.57(-21 \cdot 1,24 \cdot 3) \%$; $0 \cdot 81(-21 \cdot 0$, $22 \cdot 6) ;-2 \cdot 28(-23 \cdot 8,19 \cdot 3) \% ; 2 \cdot 21(-18 \cdot 8,23 \cdot 2) \%$ and $-2 \cdot 05$ $(-25 \cdot 7,21.6) \%$, respectively. From these, $\mathrm{DRI}^{(5)}$ and Schofield ${ }^{(42)}$ showed wider limits of agreement than the predefined maximum allowed difference of $24 \%$ and lower CCC. Root-mean-square error was roughly equal between the three remaining equations. Nevertheless, no equation presented the CI of the limits of agreement within the pre-defined maximum allowed difference range. The Bland-Altman scatterplots for the five equations are found in Fig. 1. Table 4 shows the Spearman rank correlation coefficients for the bias, in percentage, from each calculated-TEE and the estimated PAL. All coefficients were equal to or lower than $0 \cdot 10$, except for DRI equation, which was equal to $0 \cdot 27$.

\section{Discussion}

The present study demonstrated that, in low-income women with excess weight, the calculated-TEE derived from the combination between the estimated PAL and estimated BMR from five out of eleven studied predictive equations did not show significant bias when compared with the TEE-DLW. Three calculated-TEE presented its limits of agreement within the predefined maximum allowed difference range, with roughly equal root-mean-square error. Considering all parameters, the calculated-TEE obtained with the BMR yielded by the $\mathrm{FAO} / \mathrm{WHO} / \mathrm{UNU}^{(31)}$ equation performed slightly better than the others. Nevertheless, it is noteworthy that all calculatedTEE showed the CI of the limits of agreement wider than the pre-defined maximum allowed difference range of $24 \%$, indicating that none of the calculated-TEE satisfactorily estimates the TEE-DLW in the present sample. Furthermore, estimates of energy expenditure yielded by the accelerometry analysis showed good agreement with the TEE-DLW, presenting a considerably low bias and the highest CCC when compared with the calculated-TEE.

The majority of studies validate predictive equations against data derived from indirect calorimetry, including in Brazilian 
Table 3. Assessment of the agreement between the calculated total energy requirements yielded by the predictive equations multiplied by the estimated physical activity level (PAL) and the total energy expenditure (TEE) measured with doubly labelled water (DLW) in low-income women with excess weight $(n 45)$ (Mean values and standard deviations and $95 \%$ confidence intervals)

\begin{tabular}{|c|c|c|c|c|c|c|c|c|c|c|c|c|c|}
\hline \multirow[b]{2}{*}{ Equation } & \multicolumn{2}{|c|}{ TEE $(\mathrm{kJ})^{*}$} & \multirow{2}{*}{$\begin{array}{l}\text { Root-mean- } \\
\text { square } \\
\text { error }(\mathrm{kJ})\end{array}$} & \multirow[b]{2}{*}{ Bias (kJ) } & \multirow{2}{*}{$\frac{\text { LoA }}{\mathrm{LL}, \mathrm{UL} \ddagger(\mathrm{kJ})}$} & \multirow[b]{2}{*}{ Biast (\%) } & \multirow{2}{*}{$\frac{\text { LoA }}{\text { LL, UL‡ (\%) }}$} & \multirow{2}{*}{$\begin{array}{c}\text { LoA LL } \\
95 \% \mathrm{Cl}\end{array}$} & \multirow{2}{*}{$\frac{\text { LoA UL }}{95 \% \mathrm{Cl}}$} & \multirow{2}{*}{$\frac{t \text { test }}{P \S}$} & \multirow{2}{*}{$\begin{array}{c}\text { Concordance } \\
\text { correlation } \\
\text { coefficient }\end{array}$} & \multirow{2}{*}{$\begin{array}{c}\text { Maximum } \\
\text { positive } \\
\text { error (\%) }\end{array}$} & \multirow{2}{*}{$\begin{array}{l}\text { Maximun } \\
\text { negative } \\
\text { error }(\%\end{array}$} \\
\hline & Mean & SD & & & & & & & & & & & \\
\hline $\begin{array}{l}\text { TEE-DLW } \\
(\mathrm{kJ} / \mathrm{d})\end{array}$ & $8986 \cdot 8$ & 1119.9 & - & - & & - & - & - & - & & - & - & - \\
\hline $\begin{array}{l}\text { Energy intake } \\
(\mathrm{kJ} / \mathrm{d})\end{array}$ & $7522 \cdot 4$ & 1676.5 & - & - & & - & - & - & - & & - & - & - \\
\hline Accelerometryll & 8875.5 & $1178 \cdot 4$ & 1053.4 & $-111 \cdot 1$ & $-2187 \cdot 4,1965 \cdot 2$ & $-1 \cdot 2$ & $-23 \cdot 9,21 \cdot 5$ & $-30 \cdot 0,-17 \cdot 9$ & $15 \cdot 5,27 \cdot 5$ & 0.48 & 0.60 & 24 & -23 \\
\hline Anjos $^{(37)}$ & 7307.4 & 821.3 & 1948.9 & $-1679 \cdot 0$ & $-3640 \cdot 4,282 \cdot 2$ & $-20 \cdot 3$ & $-42 \cdot 5,1 \cdot 8$ & $-48 \cdot 3,-36 \cdot 6$ & $-4 \cdot 0,7 \cdot 7$ & $<0.01$ & 0.22 & 2 & -33 \\
\hline$\left.\mathrm{DR}\right|^{(5)}$ & 8796.0 & 682.0 & $1065 \cdot 2$ & -190.0 & $-2267 \cdot 6,1887.5$ & -1.5 & $-24 \cdot 3,21 \cdot 2$ & $-30 \cdot 3,-18 \cdot 3$ & $15 \cdot 2,27 \cdot 2$ & 0.53 & 0.40 & 26 & -22 \\
\hline $\mathrm{FAO}^{(31)}$ & $8854 \cdot 2$ & $542 \cdot 7$ & 1011.7 & $-132 \cdot 6$ & $-2120 \cdot 7,1855 \cdot 7$ & -0.8 & $-22 \cdot 7,21 \cdot 0$ & $-28 \cdot 4,-16 \cdot 9$ & $15 \cdot 3,26 \cdot 8$ & 0.90 & 0.41 & 23 & -24 \\
\hline Harris $^{(36)}$ & 9138.7 & 654.8 & 1003.7 & 151.9 & $-1815 \cdot 1,2119.5$ & $2 \cdot 2$ & $-19 \cdot 3,23 \cdot 9$ & $-25 \cdot 0,-13 \cdot 6$ & $18 \cdot 2,29 \cdot 6$ & 0.09 & 0.45 & 26 & -19 \\
\hline Henry(38) & $8740 \cdot 0$ & $689 \cdot 1$ & $997 \cdot 0$ & $-246 \cdot 9$ & $-2162 \cdot 1,1668 \cdot 5$ & $-2 \cdot 2$ & $-23 \cdot 3,18.9$ & $-28 \cdot 9,-17 \cdot 7$ & $13 \cdot 3,24 \cdot 4$ & 0.30 & 0.48 & 19 & -23 \\
\hline Mifflin ${ }^{(39)}$ & 8463.4 & 802.1 & 1132.6 & -523.4 & $-2514.8,1468.4$ & -5.5 & $-27.5,16.4$ & $-33 \cdot 3,-21 \cdot 7$ & $10 \cdot 6,22 \cdot 2$ & $<0.01$ & 0.44 & 20 & -23 \\
\hline Owen ${ }^{(40)}$ & $8074 \cdot 7$ & 487.4 & 1353.5 & $-912 \cdot 1$ & $-2894.7,1070 \cdot 6$ & -9.9 & $-31 \cdot 6,11 \cdot 6$ & $-37.3,-25.9$ & $5 \cdot 9,17 \cdot 3$ & $<0.01$ & 0.25 & 13 & -30 \\
\hline Oxford( $(8)$ & 8528.7 & $703 \cdot 3$ & 1114.6 & $-457 \cdot 7$ & $-2473 \cdot 1,1557.5$ & $-4 \cdot 6$ & $-26 \cdot 8,17 \cdot 4$ & $-32 \cdot 6,-21 \cdot 0$ & $11 \cdot 6,23 \cdot 3$ & 0.02 & 0.40 & 20 & -24 \\
\hline Rodrigues $^{(41)}$ & 8377.6 & $660 \cdot 7$ & 1137.6 & $-608 \cdot 8$ & $-2514.5,1297.0$ & $-6 \cdot 4$ & $-27 \cdot 3,14.5$ & $-32.8,-21 \cdot 8$ & $8 \cdot 9,20.0$ & $<0.01$ & 0.41 & 14 & -26 \\
\hline Schofield $^{(42)}$ & 9119.9 & 672.4 & $1109 \cdot 2$ & 133.5 & $-2049 \cdot 4,2316 \cdot 1$ & $2 \cdot 0$ & $-21 \cdot 7,25 \cdot 8$ & $-27 \cdot 9,-15 \cdot 4$ & $19 \cdot 5,32 \cdot 1$ & 0.14 & 0.34 & 30 & -19 \\
\hline Siervo $^{(43)}$ & $8413 \cdot 6$ & 699.6 & 1110.0 & $-572 \cdot 8$ & $-2457 \cdot 6,1311 \cdot 8$ & $-6 \cdot 0$ & $-26 \cdot 8,14.7$ & $-32 \cdot 3,-21 \cdot 3$ & $9 \cdot 2,20 \cdot 2$ & $<0.01$ & 0.44 & 15 & -27 \\
\hline
\end{tabular}

LoA, limits of agreement; UL, upper limit; LL, lower limit; DRI, Dietary Reference Intakes.

cach equation by the estimated PAL, for each woman.

† Bland-Altman percentage mean differences. Calculated by dividing the difference between the calculated-TEE and TEE-DLW by the mean between the calculated-TEE and TEE-DLW, multiplied by 100 .

¥ Lower limit and upper limit of the Bland-Altman LoA, where $95 \%$ of the differences is expected to lie between.

$\S P$ value for a ' $t$ ' test for paired samples, comparing the mean calculated-TEE with the mean TEE-DLW.

Estimates of energy expenditure based on the estimated PAL given by the accelerometry. 

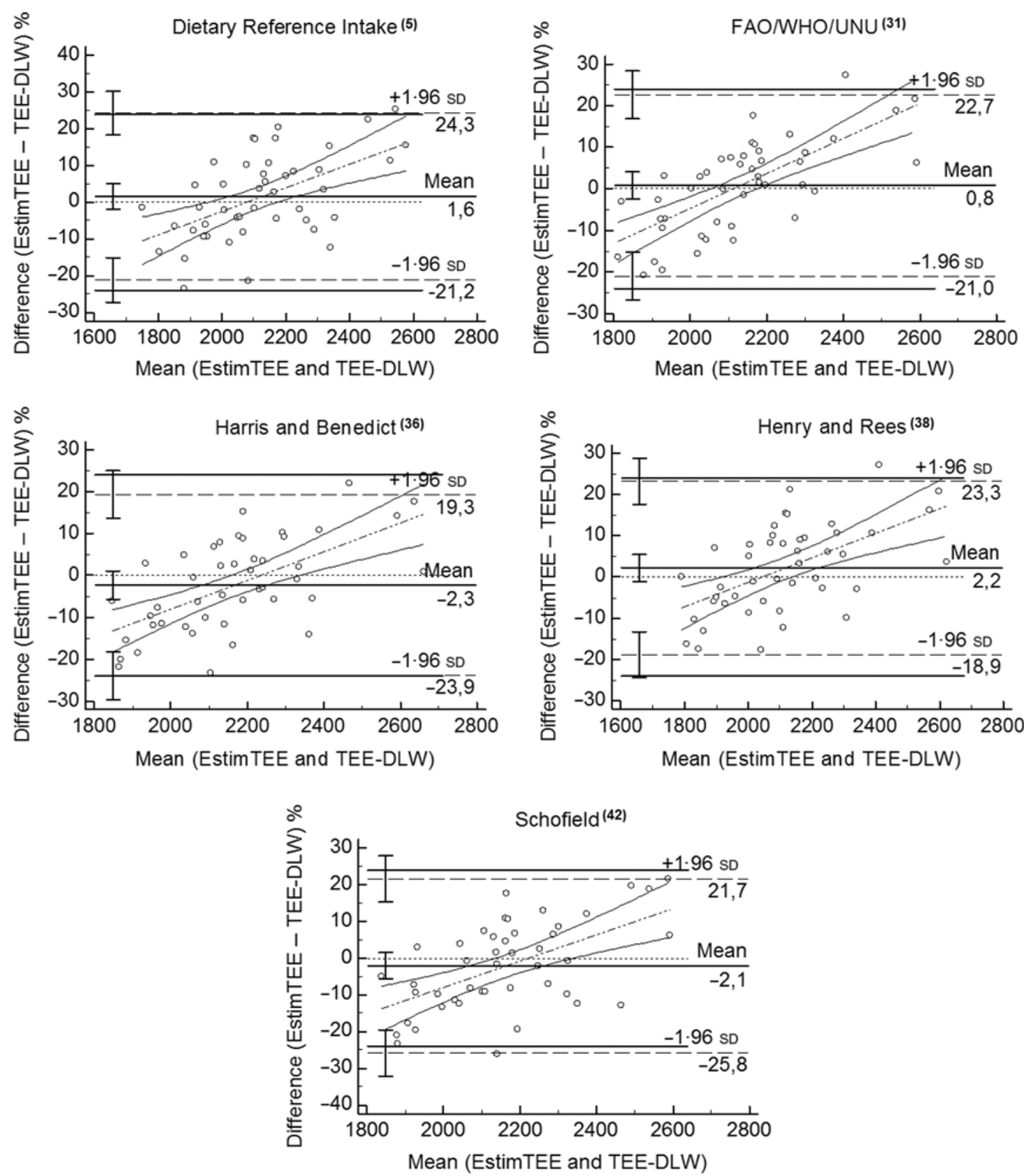

Fig. 1. Bland and Altman plots for the five equations that did not show significant bias when compared with the total energy expenditure measured with the doubly labelled water method (TEE-DLW).

populations, which is because equations are usually built to estimate $\mathrm{BMR}^{(48-50)}$. Nevertheless, as pointed by Madden et $a l^{(51)}$, in clinical practice, it is arguably more critical to use equations to estimate TEE rather than to estimate BMR, since energy deficit must be calculated considering the former and not the latter. In their recent systematic review, Madden et al. ${ }^{(51)}$ report that only four studies comparing the agreement between calculated-TEE that uses the BMR derived from predictive equations and TEE-DLW in overweight/obese adults met their inclusion criteria regarding the quality of the assessment, as compared with twenty-one studies comparing results of the equations against measured BMR.
The four studies above $\mathrm{e}^{(52-55)}$ were all conducted in US populations, with diverse backgrounds. Blanc et al. ${ }^{(52)}$ studied seventy-three obese individuals aged 70-79 years, whereas Mahabir et al. ${ }^{(53)}$ evaluated forty-four post-menopausal women with excess weight. Das et al. ${ }^{(54)}$, in turn, assessed the agreement in a group of twenty severely obese women, with a mean age approximately 37 years old. At last, Tooze et al. ${ }^{(55)}$ evaluated 314 adults with excess weight, aged 40-69 years. Hence, the comparability of our results with the studies available in the literature is somewhat complex.

More recently, Ravelli et al. ${ }^{(47)}$ investigated the agreement between the calculated-TEE obtained using the factorial method 
Table 4. Correlation matrix between the estimated physical activity level and bias (in \%) yielded by each calculated-total energy expenditure

\begin{tabular}{|c|c|c|}
\hline Equation (bias in \%) & $\begin{array}{c}\text { Spearman correlation } \\
\text { coefficient }\end{array}$ & $P$ \\
\hline Anjos et al. ${ }^{(37)}$ & -0.06 & 0.70 \\
\hline Dietary Reference Intake ${ }^{(5)}$ & $-0 \cdot 27$ & 0.07 \\
\hline FAO/WHO/ONU(31) & $0 \cdot 10$ & 0.53 \\
\hline Harris \& Benedict ${ }^{(36)}$ & 0.07 & 0.66 \\
\hline Henry \& Rees ${ }^{(38)}$ & 0.08 & 0.60 \\
\hline Mifflin et al. ${ }^{(39)}$ & 0.01 & 0.99 \\
\hline Owen ${ }^{(40)}$ & 0.11 & 0.44 \\
\hline Oxford ${ }^{(8)}$ & -0.01 & 0.93 \\
\hline Rodrigues et al. ${ }^{(41)}$ & 0.08 & 0.60 \\
\hline Schofield ${ }^{(42)}$ & -0.07 & 0.67 \\
\hline Siervo et al. ${ }^{(43)}$ & 0.07 & 0.67 \\
\hline
\end{tabular}

(i.e. multiplying equations-derived BMR by the estimated PAL) and the TEE-DLW in twenty severely obese Brazilian women before and after bariatric surgery. Although the population studied in their investigation differs from ours, since their study was conducted in the Brazilian southeast, the wealthiest region in the country, they also found that none of the investigated equations had a high accuracy when estimating the TEE-DLW of the women, especially after the weight loss induced by the bariatric surgery. Considering before-surgery values, Harris \& Benedict ${ }^{(36)}$ and $\mathrm{DRI}^{(5)}$ equations were indicated by the authors as the most suitable equations that could be used in the absence of specific equations to the target population.

It is noteworthy that two of the equations analysed in the present study, the one proposed by Anjos et al. ${ }^{(37)}$ and the other proposed by Rodrigues et l. $^{(41)}$, were both specifically developed in Brazilian studies and included women with excess weight in their samples. Nevertheless, the calculated-TEE derived using the BMR yielded by both of them presented significant bias in our investigation, being the calculated-TEE obtained using Anjos et al. ${ }^{(37)}$, the one with the highest bias of all eleven calculated-TEE. Indeed, these two equations are not very used in clinical practice, maybe due to the almost inexistent number of validation studies, like the present one, investigating these equations for Brazilian populations. Although it is a usual concern that one should only use an equation for a specific population if that equation was developed for similar populations, in the present study, the most well-known equations, such as Harris \& Benedict $^{(36)}$, FAO/WHO/UNU ${ }^{(31)}$ and Henry \& Rees ${ }^{(38)}$, which were not developed in similar populations to ours, presented a lower bias than the equations developed explicitly for Brazilian populations. This may indicate that the fact that an equation was developed using a specific population does not necessarily turn that equation the most suitable one for similar populations. At last, several studies have shown that one of the most accurate equations to predict BMR in obese individuals is proposed by Mifflin et al. ${ }^{(11,39,53)}$, which did show significant bias (5.5\%) and poor overall agreement in our study. Similar findings were also reported by Ravelli et al. ${ }^{(47)}$, which may prevent the counselling of using this equation in Brazilian populations, at least if the objective is to estimate TEE, through the factorial method, in excess weight women.

As expected in a group of obese women, the self-reported energy intake was considerably lower than the TEE-DLW.
Given that the women were weight stable, it may be concluded that there was a critical underreporting of energy intake, which is a long-discussed issue ${ }^{(56)}$, and a common phenomenon, especially in obese individuals ${ }^{(57)}$. It has also been demonstrated in Brazilian women ${ }^{(58)}$. This issue is thoroughly discussed elsewhere, with regard to the present sample ${ }^{(18)}$.

Some authors opt to include a factor to represent thermic effect of food in the calculations of the factorial method, usually $10 \%$ of the individuals' calculated-TEE ${ }^{(47)}$. In our data, this approach led to a worse overall agreement between calculated-TEE and TEE-DLW, overestimating the bias in the equations (data not shown). This overestimation may be explained by the fact that, by definition, the TEE is the result of the multiplication of the BMR by the PAL ${ }^{(31)}$. Consequently, we opted only to discuss the analysis that did not include the $10 \%$ addition of thermic effect of food in the calculated-TEE.

Regarding the estimated PAL of our sample, it indicates that the vast majority of women are sedentary and few of them are light-active. Although comparison of this data with other Brazilian women population is difficult, since few studies report it using the same data that were reported here, it is possible to conclude that our sample is much less active than other Brazilian samples. Raveli et $a l^{(47)}$ found an estimated PAL of 1.65 in twenty severely obese women before bariatric surgery, which is substantially higher than that found in the present study. As already outlined, Raveli et al. ${ }^{(47)}$ studied a significantly different population when compared with ours. Fassini et al. ${ }^{(59)}$ studying Brazilian individuals with short bowel syndrome found an estimated PAL of 1.4 for those with the disease and of 1.75 for the sex-, age- and BMI-matched controls. Vasconcellos et al. ${ }^{(60)}$, using data from 267000 Brazilian individuals, suggested a PAL of 1.53 for Brazilian women aged 20-44 years, which was substantially lower than the recommended PAL of 1.67 and close to the PAL found in the present study. It is noteworthy that the estimated PAL found in our sample is compatible with the definition given by the $\mathrm{FAO} / \mathrm{WHO} / \mathrm{UNU}$ report ${ }^{(31)}$, which states, as an example of sedentary or light activity lifestyle ' $[. .$.$] rural$ women living in villages that have electricity, piped water and nearby paved roads, who spend most of the time selling produce at home or in the marketplace, or doing light household chores and caring for children in or around their houses'. This definition matches the setting of the present study, except for the fact that our study was conducted in a metropolitan region, rather than in a rural area. Nevertheless, the benefits that a regular metropolitan area may offer in terms of PA are possibly not seen by the women in our sample, given the extremely violent setting and severe lack of infrastructure they are inserted, which makes a walk around the streets, or doing some jogging, often not a feasible option. Hence, we believe that for this population of lowincome women with excess weight, the mean PAL of 1.47 may be initially used to estimate the TEE using the factorial method.

Our study presents two crucial limitations. The first is the lack of data regarding the BMR of the sample, which could be an enriching information for the comparisons with the predictive equations. However, as the study aimed to compare the calculated-TEE obtained by the factorial method using results of the equations and accelerometers' analysis, with the TEE-DLW, and not with the BMR, the DLW method was sufficient for the analyses. 
The second limitation is that it is pivotal to consider that all of our calculations are severely dependent on the reliability of the estimated PAL; hence, if PAL was not reasonably estimated in the sample, all calculated-TEE are negatively affected. Estimates of energy expenditure based on the estimated PAL and a suitable MET value for the present sample $(3.52 \mathrm{~kJ} / \mathrm{kg}$ per $\mathrm{h})$ were calculated in order to quantify the accuracy and precision of the accelerometry analysis compared with the TEE-DLW. Although it performed better than all calculated-TEE, based on the considerably higher CCC and roughly equal bias and root-mean-square error, it is only possible to say that the accelerometry estimates of energy expenditure agreement with the TEE-DLW are moderate at best, in the present sample. Besides, the estimation of PAL with the use of triaxial accelerometry data, which yield MET values, may have some concerns, given that the basal $\mathrm{O}_{2}$ volume consumption varies among individuals, which reduces the precision of MET usage ${ }^{(34)}$. As already pointed out, corrected MET values could better represent the BMR of individuals; however, ActivPAL does not make it clear in its manual, which MET values it, uses, although it suggests the use of standard MET values (i.e. $1 \mathrm{kcal} / \mathrm{kg}$ per h or $4.184 \mathrm{~kJ} / \mathrm{kg}$ per $\mathrm{h}$ ) which may introduce important bias in our analysis.

Nevertheless, in clinical practice, the estimation of PAL is much less precise, since the practitioner relies on the reported physical activities done by the individuals, who also need to specify the amount of time they spent in each activity, and then, the practitioner matches these activities with pre-specified MET values available in the literature. Hence, although the use of accelerometers may show some imprecision, in this context, it surely may be considered a more reliable way to estimate the PAL of the individuals, supported by several studies, as outlined in the methods section ${ }^{(22-26)}$ especially in this sample of sedentary and light-physically active adults $^{(27)}$. Furthermore, the correlation analysis showed that there were no associations between the estimated PAL and the bias between each calculated-TEE and the TEE-DLW. Indeed, the equation that showed the higher correlation coefficient, but still a weak coefficient, was the DRI equation ${ }^{(5)}$, precisely the one that asks to categorize the PAL into a PA coefficient.

\section{Conclusion}

In conclusion, none of the eleven calculated-TEE, estimated using the factorial method, showed the CI of the limits of agreement within the pre-defined maximum acceptable difference range of $24 \%$. This indicates that the use of these equations may not be sufficiently precise to estimate TEE using the factorial method in the context of the present study. Nevertheless, in the absence of specific equations for this population of low-income women with excess weight, the use of the equations of FAO/ WHO/UNU ${ }^{(31)}$ may be considered in conjunction with a mean PAL of 1.47 to estimate the TEE, using the factorial method.

\section{Acknowledgements}

The present study is funded by the Brazilian National Council for Scientific and Technologic Development (CNPq), process no. 552194/2011-5. CNPq had no role in the design, analysis or writing of this article.
M. L. M., I. S. V. M., A. G. C., K. P., E. F., I. R. O. M. P. and N. B. B. collected and analysed the data; M. L. M., I. S. V. M., I. R. O. M. P. and N. B. B. wrote the draft of the manuscript and H. S. F., T. M. T. F. and A. L. S. critically reviewed the manuscript. All authors read and approved the final version of the manuscript.

The authors declare no conflicts of interest.

\section{References}

1. Ng M, Fleming T, Robinson M, et al. (2014) Global, regional, and national prevalence of overweight and obesity in children and adults during 1980-2013: a systematic analysis for the Global Burden of Disease Study. Lancet 384, 766-781.

2. Ford ND, Patel SA \& Narayan KM (2017) Obesity in low- and middle-income countries: burden, drivers, and emerging challenges. Ann Rev Public Health 38, 145-164.

3. Ministério da Saúde (2018) Vigilancia de Fatores de Risco e Proteção para Doenças Crônicas por Inquérito Telefônico VIGITEL 2017: estimativas sobre frequência e distribuição sociodemográfica de fatores de risco e proteção para doenças crônicas nas capitais dos 26 estados brasileiros e no Distrito Federal em 2016 (Surveillance of Chronic Diseases Risk and Protection Factors by Telephone Survey - VIGITEL 2017: Estimates on Frequency and Sociodemographic Distribution of Risk Factors and Protection for Chronic Diseases in the Capitals of the 26 Brazilian States and the Federal District in 2016), 130p. Brasília, Brasil.

4. Psota T \& Chen KY (2013) Measuring energy expenditure in clinical populations: rewards and challenges. Eur J Clin Nutr 67, 436-442.

5. Institute of Medicine (2005) Dietary Reference Intakes for Energy, Carbohydrate, Fiber, Fat, Fatty Acids, Cholesterol, Protein, and Amino Acids. Washington, DC: National Academies Press.

6. Westerterp KR (2017) Doubly labelled water assessment of energy expenditure: principle, practice, and promise. Eur $J$ Appl Physiol 117, 1277-1285.

7. Scagliusi FB \& Lancha Júnior AH (2005) The study of energy expenditure through doubly labelled water: principles, use and applications. Rev Nutr 18, 541-551.

8. Henry CJK (2005) Basal metabolic rate studies in humans: measurement and development of new equations. Public Health Nutr 8, 1133-1152.

9. Weijs PJ (2008) Validity of predictive equations for resting energy expenditure in US and Dutch overweight and obese class I and II adults aged 18-65 y. Am J Clin Nutr 88, 959-970.

10. Sabounchi NS, Rahmandad H \& Ammerman A (2013) Bestfitting prediction equations for basal metabolic rate: informing obesity interventions in diverse populations. Int J Obes (Lond) 37, 1364-1370.

11. Frankenfield D, Roth-Yousey L, Compher C, et al. (2005) Comparison of predictive equations for resting metabolic rate in healthy nonobese and obese adults: a systematic review. $J$ Am Diet Assoc 105, 775-789.

12. Cancello R, Soranna D, Brunani A, et al. (2018) Analysis of predictive equations for estimating resting energy expenditure in a large cohort of morbidly obese patients. Front Endocrinol (Lausanne) 9, 367 .

13. Scientific Advisory Committee on Nutrition (2011) Dietary Reference Values for Energy. https://www.gov.uk/government/ uploads/system/uploads/attachment_data/file/339317/SACN_ Dietary_Reference_Values_for_Energy.pdf (accessed February 2019).

14. Lee IM \& Shiroma EJ (2014) Using accelerometers to measure physical activity in large-scale epidemiological studies: issues and challenges. Br J Sports Med 48, 197-201. 
15. Florêncio TM, Bueno NB, Clemente AP, et al. (2015) Weight gain and reduced energy expenditure in low-income Brazilian women living in slums: a 4-year follow-up study. $\mathrm{Br}$ J Nutr 114, 462-471.

16. World Health Organization (1995) Physical Status: The Use and Interpretation of Anthropometry. Geneva, Switzerland: World Health Organization.

17. Monteiro JP (2007) Consumo Alimentar: Visualizando porções. Série Nutrição e Metabolismo (Food Consumption: Viewing Portions. Nutrition and Metabolism Series). Rio de Janeiro, Brazil: Guanabara Koogan.

18. Lins IL, Bueno NB, Grotti Clemente AP, et al. (2016) Energy intake in socially vulnerable women living in Brazil: assessment of the accuracy of two methods of dietary intake recording using doubly labeled water. J Acad Nutr Diet 116, 1560-1567.

19. Coward WA, Roberts SB \& Cole TJ (1988) Theoretical and practical considerations in the doubly labelled water $(2 \mathrm{H} 2(18) \mathrm{O})$ method for the measurement of carbon dioxide production rate in humans. Eur J Clin Nutr 42, 207-212.

20. International Atomic Energy Agency (2009) Assessment of Body Composition and Total Energy Expenditure in Humans Using Stable Isotope Techniques. Vienna: IAEA Human Health Related Publications.

21. Speakman JR (1998) The history and theory of the doubly labeled water technique. Am J Clin Nutr 68, 932-938.

22. Grant PM, Ryan CG, Tigbe WW, et al. (2006) The validation of a novel activity monitor in the measurement of posture and motion during everyday activities. Br J Sports Med 40, 992-997.

23. Ryan CG, Grant PM, Tigbe WW, et al. (2006) The validity and reliability of a novel activity monitor as a measure of walking. $\mathrm{Br}$ J Sports Med 40, 779-784.

24. Lyden K, Keadle SK, Staudenmayer J, et al. (2017) The activPALTM accurately classifies activity intensity categories in healthy adults. Med Sci Sports Exerc 49, 1022-1028.

25. van Nassau F, Chau JY, Lakerveld J, et al. (2015) Validity and responsiveness of four measures of occupational sitting and standing. Int J Behav Nutr Phys Act 12, 144.

26. Kozey-Keadle S, Libertine A, Lyden K, et al. (2011) Validation of wearable monitors for assessing sedentary behavior. Med Sci Sports Exerc 43, 1561-1567.

27. Alberto FP, Nathanael M, Mathew B, et al. (2017) Wearable monitors criterion validity for energy expenditure in sedentary and light activities. J Sport Health Sci 6, 103-110.

28. Food and Agriculture Organization, World Health Organization \& United Nations University (1985) Energy and Protein Requirements. Report of a Joint FAO/WHO/UNU Expert Consultation. Food and Nutrition Technical Report Series no. 724. Geneva: WHO.

29. James WPT \& Schofield EC (1990) Human Energy Requirements: A Manual for Planners and Nutritionists. Oxford, UK: Oxford University Press.

30. Harrington DM, Welk GJ \& Donnelly AE (2011) Validation of MET estimates and step measurement using the ActivPAL physical activity logger. J Sports Sci 29, 627-633.

31. Food and Agriculture Organization (2001) Human energy requirements. Report of a Joint $\mathrm{FAO} / \mathrm{WHO} / \mathrm{UNU}$ Expert Consultation, Rome. Food and Nutrition Technical Report Series. Rome: FAO.

32. Ainsworth BE, Haskell WL, Whitt MC, et al. (2000) Compendium of physical activities: an update of activity codes and MET intensities. Med Sci Sports Exerc 32, 498-516.

33. Jetté M, Sidney K \& Blümchen G (1990) Metabolic equivalents (METS) in exercise testing, exercise prescription, and evaluation of functional capacity. Clin Cardiol 13, 555-565.
34. Byrne NM, Hills AP, Hunter GR, et al. (2005) Metabolic equivalent: one size does not fit all. J Appl Physiol (1985) 99, 1112-1119.

35. Kozey S, Lyden K, Staudenmayer J, et al. (2010) Errors in MET estimates of physical activities using $\left.3.5 \mathrm{~mL} \times \mathrm{kg}^{(-1}\right) \times \min \left({ }^{-1}\right)$ as the baseline oxygen consumption. J Phys Act Health 7, 508-516.

36. Harris JA \& Benedict FG (1919) A biometric study of human basal metabolism. Proc Natl Acad Sci U S A 4, 370-373.

37. Anjos LA, Wahrlich V \& Vasconcellos MT (2014) BMR in a Brazilian adult probability sample: the nutrition, physical activity and health survey. Public Health Nutr 17, 853-860.

38. Henry CJK \& Rees DG (1991) New predictive equations for the estimation of basal metabolic rate in tropical peoples. EurJ Clin Nutr 45, 177-185.

39. Mifflin MD, St Jeor ST, Hill LA, et al. (1990) A new predictive equation for resting energy expenditure in healthy individuals. Am J Clin Nutr 51, 241-247.

40. Owen OE, Kavle E, Owen RS, et al. (1986) A reappraisal of caloric requirements in healthy women. Am J Clin Nutr 44, 1-19.

41. Rodrigues AE, Mancini MC, Dalcanale L, et al. (2010) Characterization of metabolic resting rate and proposal of a new equation for a female Brazilian population. Arq Bras Endocrinol Metabol 54, 470-476.

42. Schofield WN (1985) Predicting basal metabolic rate: new standards and review of previous work. Hum Nutr Clin Nutr 39, $5-41$.

43. Siervo M, Boschi V \& Falconi C (2003) Which REE prediction equation should we use in normal-weight, overweight and obese women? Clin Nutr 22, 193-204.

44. Bland JM \& Altman DG (2003) Applying the right statistics: analyses of measurement studies. Ultrasound Obstet Gynecol 22, 85-93.

45. Lin LI (1989) A concordance correlation coefficient to evaluate reproducibility. Biometrics 45, 255-268.

46. Lu MJ, Zhong WH, Liu YX, et al. (2016) Sample size for assessing agreement between two methods of measurement by Bland-Altman method. Int J Biostat 12, https://doi.org/10. 1515/ijb-2015-0039.

47. Ravelli MN, Schoeller DA, Crisp AH, et al. (2018) Accuracy of total energy expenditure predictive equations after a massive weight loss induced by bariatric surgery. Clin Nutr ESPEN 26, 57-65.

48. Santos RD, Suen VM, Marchini JS, et al. (2011) What is the best equation to estimate the basal energy expenditure of climacteric women? Climacteric 14, 112-116.

49. Fett CA, Fett WC \& Marchini JS (2006) Gasto energético de repouso medido vs. estimado e relação com a composição corporal de mulheres (Measured resting energy expenditure vs. estimated and relationship with body composition of women). Arq Bras Endocrinol Metab 50, 1050-1058.

50. Poli VF, Sanches RB, Moraes AS, et al. (2016) Resting energy expenditure in obese women: comparison between measured and estimated values. Br J Nutr 116, 1306-1313.

51. Madden AM, Mulrooney HM \& Shah S (2016) Estimation of energy expenditure using prediction equations in overweight and obese adults: a systematic review. J Hum Nutr Diet 29, 458-476.

52. Blanc S, Schoeller DA, Bauer D, et al. (2004) Energy requirements in the eighth decade of life. Am J Clin Nutr 79, 303-310.

53. Mahabir S, Baer DJ, Giffen C, et al. (2006) Comparison of energy expenditure estimates from 4 physical activity questionnaires with doubly labeled water estimates in postmenopausal women. Am J Clin Nutr 84, 230-236.

54. Das SK, Saltzman E, McCrory MA, et al. (2004) Energy expenditure is very high in extremely obese women. J Nutr 134, $1412-1416$. 
55. Tooze JA, Schoeller DA, Subar AF, et al. (2007) Total daily energy expenditure among middle-aged men and women: the OPEN Study. Am J Clin Nutr 86, 382-387.

56. Schoeller DA (1995) How accurate is self-reported dietary energy intake? Nutr Rev 48, 373-379.

57. Heitmann BL \& Lissner L (1995) Dietary underreporting by obese individuals-is it specific or non-specific? BMJ 311, 986-989.

58. Scagliusi FB, Ferrioli E, Pfrimer K, et al. (2008) Underreporting of energy intake in Brazilian women varies according to dietary assessment: a cross-sectional study using doubly labeled water. J Am Diet Assoc 108, 2031-2040.

59. Fassini PG, Pfrimer K, Ferriolli E, et al. (2016) Assessment of energy requirements in patients with short bowel syndrome by using the doubly labeled water method. Am J Clin Nutr $103,77-82$.

60. Vasconcellos MT \& Anjos LA (2003) A simplified method for assessing physical activity level values for a country or study population. Eur J Clin Nutr 57, 1025-1033. 